\title{
Tracking uncertainties in the causal chain from human activities to climate
}

\author{
Michael J. Prather, ${ }^{1,2}$ Joyce E. Penner, ${ }^{3}$ Jan S. Fuglestvedt, ${ }^{4}$ Atsushi Kurosawa, ${ }^{5}$ \\ Jason A. Lowe, ${ }^{6}$ Niklas Höhne, ${ }^{7}$ Atul K. Jain, ${ }^{8}$ Natalia Andronova, ${ }^{3}$ Luiz Pinguelli, ${ }^{9}$ \\ Chris Pires de Campos, ${ }^{10}$ Sarah C. B. Raper, ${ }^{11}$ Ragnhild B. Skeie, ${ }^{4}$ Peter A. Stott, ${ }^{6}$ \\ John van Aardenne, ${ }^{12}$ and Fabian Wagner ${ }^{13}$ \\ Received 31 October 2008; revised 5 January 2009; accepted 28 January 2009; published 12 March 2009.
}

[1] Attribution of climate change to individual countries is a part of ongoing policy discussions, e.g., the Brazil proposal, and requires a quantifiable link between emissions and climate change. We present a constrained propagation of errors that tracks uncertainties from human activities to greenhouse gas emissions, to increasing abundances of greenhouse gases, to radiative forcing of climate, and finally to climate change, thus following the causal chain for greenhouse gases emitted by developed nations since national reporting began in 1990. Errors combine uncertainties in the forward modeling at each step with top-down constraints on the observed changes in greenhouse gases and temperatures. Global surface temperature increased by $+0.11{ }^{\circ} \mathrm{C}$ in 2003 due to the developed nations' emissions of Kyoto greenhouse gases from 1990 to 2002 . The uncertainty range, $+0.08{ }^{\circ} \mathrm{C}$ to $+0.14{ }^{\circ} \mathrm{C}(68 \%$ confidence $)$, is large considering that the developed countries emissions are well known for this period and climate system modeling uncertainties are constrained by observations. Citation: Prather, M. J., et al. (2009), Tracking uncertainties in the causal chain from human activities to climate, Geophys. Res. Lett., 36, L05707, doi:10.1029/2008GL036474.

\section{Introduction}

[2] A wide range of human activities are responsible for greenhouse gas (GHG) emissions and are designated for national reporting under the National Greenhouse Gas Inventories Programme (NGGIP) of the Intergovernmental Panel on Climate Change (IPCC) [1997]. The NGGIP describes methodologies for converting activities into emissions reported to the United Nations Framework Convention

\footnotetext{
${ }^{1}$ Earth System Science, University of California, Irvine, California, USA.

${ }^{2}$ Jefferson Science Fellow, U.S. State Department, Washington, D. C., USA.

${ }^{3}$ AOSS, University of Michigan, Ann Arbor, Michigan, USA.

${ }^{4}$ CICERO, Oslo, Norway.

${ }^{5}$ Research and Development Division, Institute of Applied Energy,

Tokyo, Japan.

${ }^{6}$ Met Office, Reading, UK.

${ }^{7}$ Ecofys Germany, Cologne, Germany.

${ }^{8}$ Atmospheric Sciences, University of Illinois at Urbana-Champaign, Urbana, Illinois, USA.

${ }^{9}$ COPPE, University of Rio de Janeiro, Rio de Janeiro, Brazil.

${ }^{10}$ PETROBRAS, Rio de Janeiro, Brazil.

${ }^{11}$ CATE, Manchester Metropolitan University, Manchester, UK.

${ }^{12}$ JRC, Institute for Environment and Sustainability, Ispra, Italy.

${ }^{13}$ IIASA, Laxenburg, Austria.
}

Copyright 2009 by the American Geophysical Union. 0094-8276/09/2008GL036474 on Climate Change (UNFCCC) [2004]. Such emissions are responsible for most of the observed rise in GHGs [Denman et al., 2007]. 20th-century warming has been attributed to this rise with differing approaches and statistical certainty [Hansen, 1988; Mitchell et al., 2001; Hegerl et al., 2007]. Absolute climate change caused by individual countries' emissions has not been examined with the same effort. This paper presents the first analysis of errors following the causal chain from human activities, to GHG emissions, to the increasing GHG abundances, to the radiative forcing of climate, and finally to climate change. At each step, errors are not only propagated but evaluated and revised based on independent information and top-down constraints on the observed changes in GHGs and climate (Figure 1).

[3] Scientific study of the relative amount of climate change that could be attributed to national emissions was stimulated by Brazil's proposal to the UNFCCC [Filho and Miguez, 1998] in which commitments to reduce GHG emissions would be based on the developed (Annex-I) nations' historical contribution to climate change. A number of subsequent scientific studies [den Elzen and Schaeffer, 2002; den Elzen et al., 2005; Rosa et al., 2004; Andronova and Schlesinger, 2004; Höhne and Blok, 2005; Trudinger and Enting, 2005; Rive et al., 2006] have examined issues in applying the Brazil proposal: e.g., non-linear additivity of $\mathrm{CO}_{2}$ increases; analysis of modeling sensitivities; political choice of the beginning/end dates for emissions attribution and the date for evaluation of climate change. For the most part, these studies focused on relative climate change within a group of nations, and none addressed the scientific uncertainty in attributing absolute climate change. The problem with relative attribution is that it hides known systematic biases: simply put, our best models for emissions, atmospheric composition, and climate change do not always match observations. Such systematic errors can affect relative attribution, even among Annex-I nations.

[4] As a case study, we choose the period from 1990 to 2003 and evaluate the climate change caused by total emissions from the developed nations during this period. This case is optimal in terms of uncertainties since it spans a time period with the best data on national reporting, independent emissions inventories, atmospheric chemistry, the carbon cycle, GHG abundances, aerosols, radiative forcing $(\mathrm{RF})$, and climate change. We restrict our assessment to Annex-I countries with available reporting (denoted Annex-IR, not including former Soviet states). Step 1 (Figure 1) begins with UNFCCC reported emissions and uncertainties for years 1990 through 2002 based on the official reports. Step 2 uses independent data to revise the uncertainty 


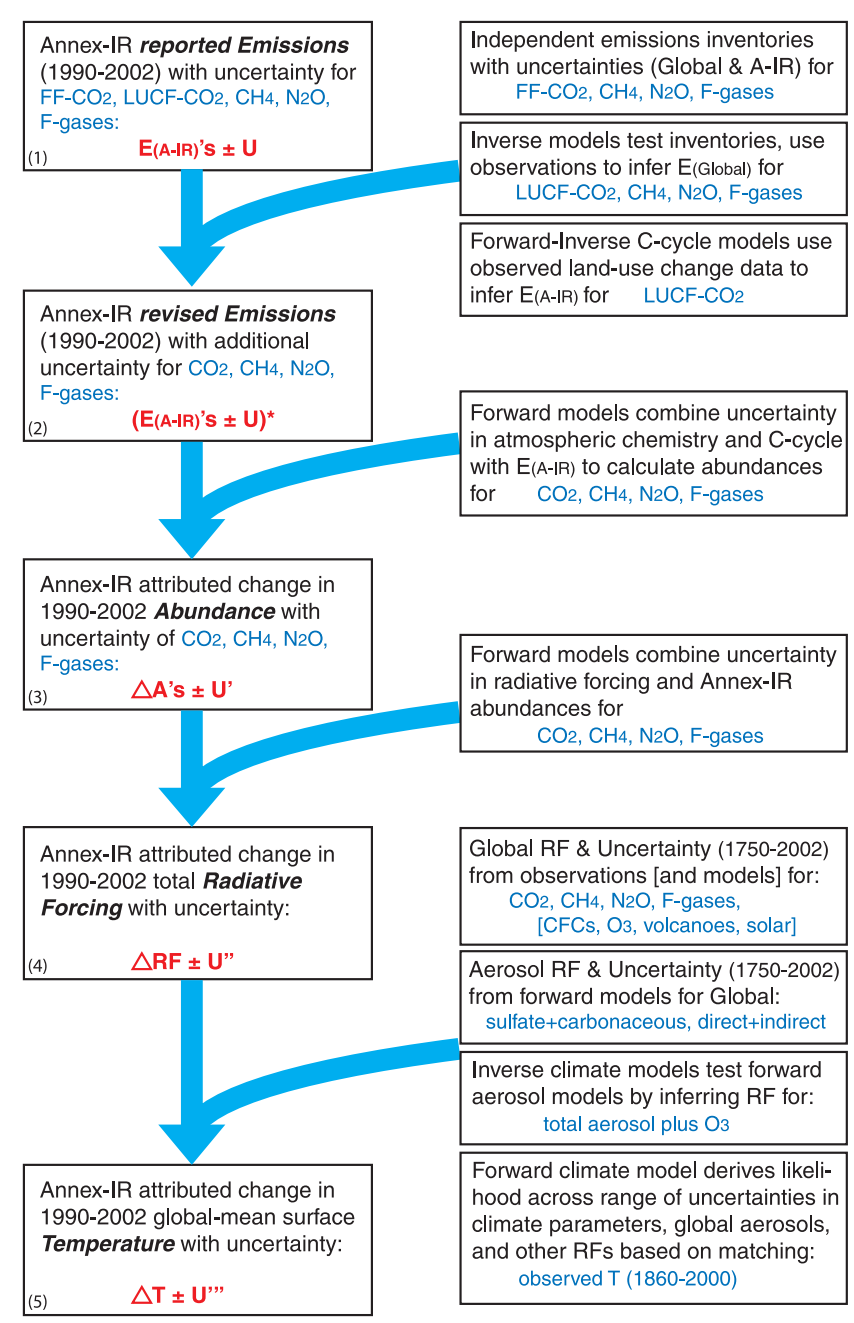

Figure 1. Flow path of this analysis.

associated with the reported emissions. Step 3 propagates these emissions with uncertainties into changes in GHG abundances, adding uncertainty derived from the emissionto-abundance models. Step 4 calculates the RF perturbation by Annex-IR, combining uncertainties across the GHGs and in the modeling of RF. Step 5 uses a large set of parametric climate models, spanning uncertainties in climate modeling and the history of RF, to propagate the Annex-IR perturbations of RF into a temperature change. For the period from 1990 to 2003 , Annex-IR activities caused a $0.11 \pm 0.03^{\circ} \mathrm{C}$ warming (16\%-to- $84 \%$ confidence range), while worldwide anthropogenic GHG emissions caused a $0.33^{\circ} \mathrm{C}$ warming.

\section{Emissions}

[5] Total Annex-IR reported emissions of $\mathrm{CO}_{2}, \mathrm{CH}_{4}$, and $\mathrm{N}_{2} \mathrm{O}$ vary by only $10 \%$ annually over the years 1990 through 2002, but emissions of some fluorinated gases (F-gases) such as $\mathrm{HFC}-134 \mathrm{a}, \mathrm{CF}_{4}$, and $\mathrm{SF}_{6}$ have large, shifting trends (see auxiliary material Tables S1-S2). ${ }^{1}$ Average total emissions are about 13,000 million tons $\mathrm{CO}_{2}$-equivalent per year. Fossil-fuel (FF) is used to describe anthropogenic $\mathrm{CO}_{2}$ emissions from mining and combustion of fossil fuels as well as

\footnotetext{
${ }^{1}$ Auxiliary materials are available in the HTML. doi:10.1029/ 2008GL036474.
}

cement manufacture, but not emissions from land-use change and forestry (LUCF). For the period 1990-2002, Annex-IR FF $\mathrm{CO}_{2}$ emissions are about half of the World's total, but Annex-IR $\mathrm{CH}_{4}$ and $\mathrm{N}_{2} \mathrm{O}$ emissions are much less than half. Even within Annex-IR, countries show a different mix of GHGs: EU-15 (pre-2004 members) emissions are about 63\% of those from the USA for most GHG, but they are notably larger for $\mathrm{N}_{2} \mathrm{O}$ and less negative for LUCF $\mathrm{CO}_{2}$. This differing mix of GHG emissions alters the impact of historical emissions on current climate change [den Elzen et al., 2005] and further implies that errors in emissions, atmospheric residence time, or radiative forcing of one GHG can change the relative impact between countries.

[6] Uncertainties in 1990-2002 UNFCCC reported emissions for the big-three GHGs $\left(\mathrm{CO}_{2}, \mathrm{CH}_{4}, \mathrm{~N}_{2} \mathrm{O}\right)$ are calculated from the probability distributions, either normal or lognormal, for each sector/category based on NGGIP methodologies. Default factors for these uncertainties are given in the Table S3. The probability distribution function (PDF) for total Annex-IR emissions assumes: all countries share a common PDF per category; but uncertainties across sectors or categories are independent. Where possible we represent uncertainty as a PDF. If only a ' \pm ' or 'lower/upper' range is given, it represents the $16 \%$-to- $84 \%$ range (68\%-confidence interval, \pm 1 sigma for a normal distribution).

[7] Annex-IR $\mathrm{FF} \mathrm{CO}_{2}$ reported emissions have no obvious bias when compared with independent emission inventories from EDGAR [Olivier and Berdowski, 2001; van Aardenne et al., 2001], CDIAC [Marland et al., 2003] and International Energy Agency [2004], yet the overall uncertainty from reporting is very small and does not encompass values from the independent inventories. This is seen clearly for 1995 (Figure S1a) and the time series 1990-2002 (Figure S2a). Thus, for Step 2 we accept the reported $\mathrm{FF} \mathrm{CO}_{2}$ emissions but increase the uncertainty to $\pm 6 \%(3.11 \pm 0.19 \mathrm{GtC} / \mathrm{yr}$ averaged over 1990-2002; Figure 2a).

[8] LUCF $\mathrm{CO}_{2}$ emissions are far more difficult to evaluate with independent scientific data. The 1990s mean flux reported from Annex-IR is $-0.36 \mathrm{GtC} / \mathrm{yr}$ while that derived from land-use change data is $-0.08 \mathrm{GtC} / \mathrm{yr}$ [Ramankutty and Foley, 1998, 1999]. Calculation of Annex-IR LUCF fluxes with the ISAM carbon-cycle model [Jain and Yang, 2005] using three different land-use change data sets gives annual fluxes varying between -0.1 and $+0.1 \mathrm{GtC} / \mathrm{yr}$ (Figure S2a). While UNFCCC reporting appears to be biased low, it may reflect NGGIP methods, which limit activities and processes that can be counted as LUCF flux when compared to the inclusive nature of scientific models (e.g., the ISAM model includes the non-NGGIP effects of climate change and $\mathrm{CO}_{2}$ fertilization). Without a more thorough evaluation of LUCF reporting to determine possible bias [Ito et al., 2008], we adopt an uncertainty of $\pm 0.40 \mathrm{GtC} / \mathrm{yr}$, which brings all estimates within the $16 \%$-to- $84 \%$ confidence interval. Combining these PDFs, the average $\mathrm{FF}+\mathrm{LUCF} \mathrm{CO} \mathrm{C}_{2}$ emissions are $2.75 \pm 0.44 \mathrm{GtC} / \mathrm{yr}$ (Figure 2a).

[9] Average $\mathrm{CH}_{4}$ emissions from Annex-IR reporting are $66 \mathrm{Tg} / \mathrm{yr} \pm 13 \%$. Annex-IR emissions from the EDGAR inventory are $17 \%$ greater. The EDGAR emissions have high credibility because their global emissions accurately match those derived using an atmospheric chemistry inverse model (see auxiliary material and Figure S2b). Consequently, we believe UNFCCC reported emissions are biased low and choose 

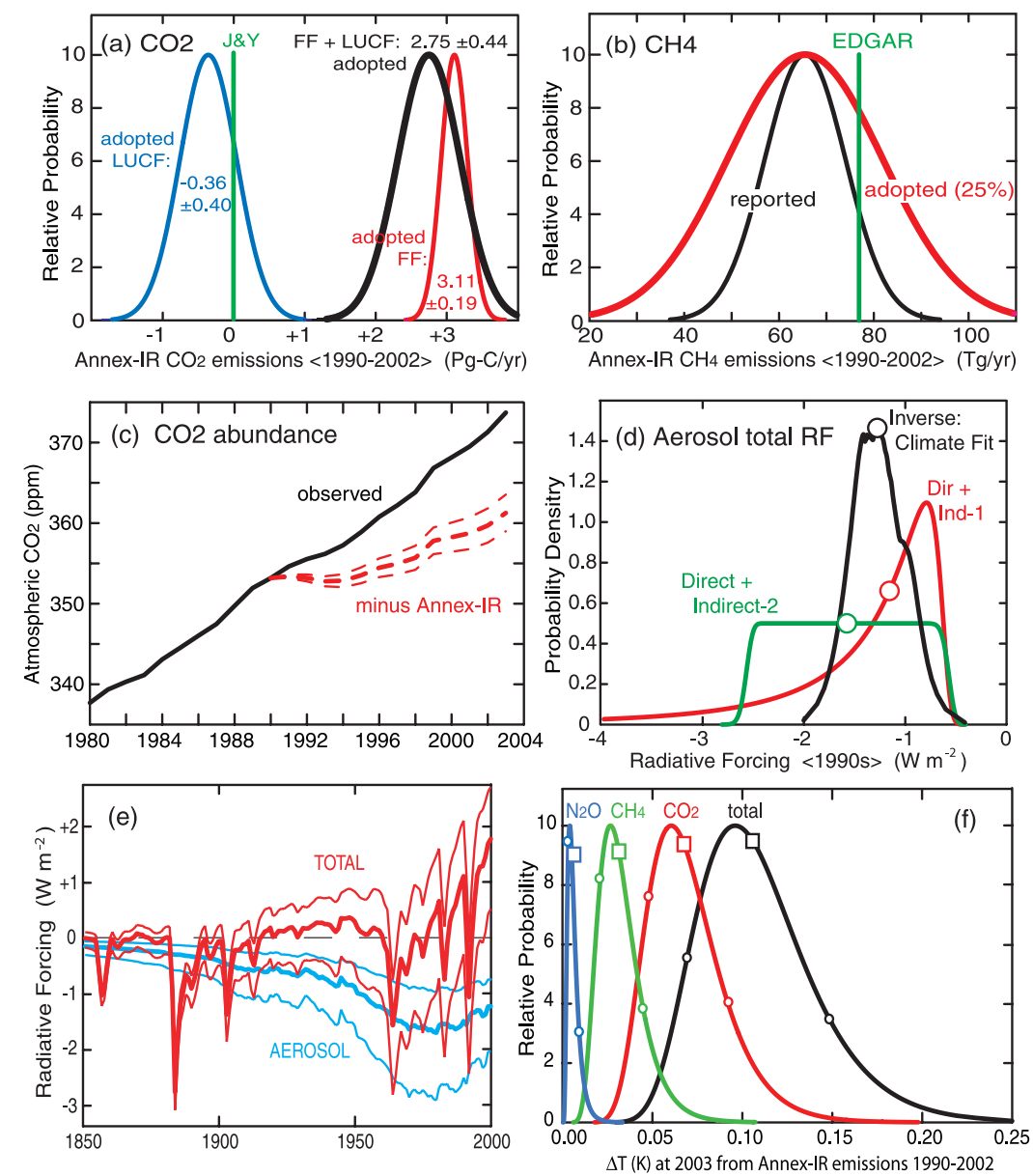

Figure 2. Probability distribution functions (PDFs) derived in this analysis. (a) PDF of Annex-IR $\mathrm{CO}_{2}$ emissions (19902002) adopted for FF, LUCF and FF + LUCF. LUCF emissions from Jain and Yang [2005] have a single value. (b) PDF of Annex-IR $\mathrm{CH}_{4}$ emissions (1990-2002) showing reported uncertainty, EDGAR best value [van Aardenne et al., 2001], and the final adopted uncertainty. (c) Reduction in atmospheric $\mathrm{CO}_{2}$ abundance (ppm) from the observed increase as calculated without Annex-IR emissions, showing the 16\%-to-84\%-confidence range. (d) PDF of aerosol total RF from two forward models of the aerosol indirect RF and inverse climate modeling. Open circles are median values. (e) Historical (1850-2000) total RF (red) and total aerosol RF (blue) used in this study with 16\%-to- $84 \%$ confidence range (thin bounding lines). (f) PDFs of temperature change (K) from 1990 to 2003 caused by Annex-IR 1990-2002 emissions of $\mathrm{N}_{2} \mathrm{O}, \mathrm{CH}_{4}$, and $\mathrm{CO}_{2}$. Total includes also the F-gases.

to address this by increasing the uncertainty to $\pm 25 \%$ ("Adopted" in Figure 2b) to encompass the EDGAR emissions.

[10] Average $\mathrm{N}_{2} \mathrm{O}$ emissions from Annex-IR reporting are $3.1(-1.0,+2.1) \mathrm{Tg} / \mathrm{yr}$, where the highly asymmetric uncertainty range follows from the log-normal uncertainties in the NGGIP categories (Figure S1b and Table S3). Annex-IR emissions from the EDGAR inventory are greater, $3.7 \mathrm{Tg} / \mathrm{yr}$, but within the uncertainty range. Confidence in the EDGAR $\mathrm{N}_{2} \mathrm{O}$ emissions is not as great as for $\mathrm{CH}_{4}$ because their global emissions are $40 \%$ greater than those from the inverse model (see auxiliary material and Figure S2c). Thus, we find no reason to adjust the reported $\mathrm{N}_{2} \mathrm{O}$ emissions.

\section{Atmospheric Composition}

[11] The incremental change in atmospheric abundance attributable to Annex-IR (Step 3) is calculated with the emission PDFs (Step 2) using forward models that include uncertainties in atmospheric chemistry or carbon cycle. For $\mathrm{CO}_{2}$, the emission PDF is combined with three parametric variants of the ISAM model [Cao and Jain, 2005] chosen to represent model uncertainty $(16 \%-50 \%-84 \%$ range $)$. These variants reproduce the observed $\mathrm{CO}_{2}$ abundances and include uncertainty in natural sources. Cessation of Annex-IR emissions in 1990 drops atmospheric $\mathrm{CO}_{2}$ by $12.4 \pm 2.4 \mathrm{ppm}$ (micromoles per mole) by January 2003 (Figure 2c). Forward modeling of $\mathrm{CH}_{4}$ abundances adopts a $\pm 18 \%$ uncertainty in atmospheric lifetime and chemical feedbacks that determine the response time. The reduction in $\mathrm{CH}_{4}$ from cessation of Annex-IR emissions reaches $180 \pm 49 \mathrm{ppb}$ (nanomoles per mole) by January 2003. The reduction in $\mathrm{N}_{2} \mathrm{O}$ reaches 5.0 $(-1.4,+4.3) \mathrm{ppb}$. The abundance reductions in $\mathrm{CO}_{2}$ and $\mathrm{CH}_{4}$ depend on the schedule of emission reductions, even within the 12-year period here; whereas those in $\mathrm{N}_{2} \mathrm{O}$ are insensitive because of its longer lifetime.

\section{Radiative Forcing}

[12] The Annex-IR change in radiative forcing $(\Delta R F$, Step 4) combines the PDFs for all the GHG changes from 
1990 through 2002 with an uncorrelated $\pm 7 \%$ one-sigma uncertainty in converting from abundance to RF [Forster et al., 2007]. By January 2003 the $\Delta \mathrm{RF}$ from all Annex-IR GHGs is $0.30 \pm 0.05 \mathrm{~W} \mathrm{~m}^{-2}$ (Figure S3).

[13] As part of Step 5 - the climate modeling of Annex-IR temperature change $(\Delta \mathrm{T})$ from $\Delta \mathrm{RF}-$ we must define the total, natural-plus-anthropogenic RF from 1850 to 2002. The abundances of the well mixed GHGs $\left(\mathrm{CO}_{2}, \mathrm{CH}_{4}, \mathrm{~N}_{2} \mathrm{O}\right.$, $\mathrm{F}$-gases, and chlorofluorocarbons) over the last few centuries are well known, and after converting to RF [Ramaswamy et al., 2001] the overall uncertainty is less than $\pm 10 \%$ (i.e., $+2.5 \mathrm{~W} \mathrm{~m}^{-2}$ in 2002). The RF from stratospheric $\mathrm{O}_{3}$ depletion $\left(-0.15 \mathrm{~W} \mathrm{~m}^{-2}\right.$ in $\left.2002, \pm 67 \%\right)$ scales with stratospheric chlorine levels, and that from increasing tropospheric $\mathrm{O}_{3}\left(+0.38 \mathrm{~W} \mathrm{~m}^{-2}\right.$ in $\left.2002, \pm 47 \%\right)$ is based on atmospheric chemistry modeling. The largest uncertainty in total RF lies with aerosols, specifically their RF history and the aerosol indirect effect on clouds [Penner et al., 2001; Forster et al., 2007]. Two alternate forward-model estimates of the aerosol indirect RF are derived here, averaged, and merged with the direct aerosol RF into a total aerosol RF for the 1990s (see Figure S4), which is then scaled with emission activity indices from 1850 to 2002 .

[14] Given the importance of the aerosol indirect RF, we add an independent approach based on top-down climate modeling [Stott et al., 2006; Hegerl et al., 2007]. This inverse model uses the observed climate record and the known RF (from natural forcings plus well mixed GHGs) to derive a PDF for the "missing" RF, presumably the sum of aerosols and ozone. Subtracting the ozone RF gives the inverse-model aerosol total RF for the 1990s (Figure 2d). The PDFs and median values (denoted by open circles for all lines) for the two forward models and one inverse model are remarkably consistent, justifying our use of the average forward-model RFs in the Step 5.

[15] The RF histories from 1850 to 2000 for both total RF and aerosol RF, along with their 16\%-to- $84 \%$-confidence ranges, are shown in Figure 2e. Volcanoes show sharp cooling spikes; aerosol cooling peaked around 1980; and there has been a clear and steady rise in total RF since 1970. The full PDF of total RF is asymmetric and calculated from the PDFs of GHGs and aerosols. Individual RF components over the first- and second-halves of 20th century (Figure S5) show the increasing importance of volcanic cooling over the century as well as the rise in GHGs. With the instantaneous RF chart as in IPCC, it is not obvious that from 1950 to 2000 volcanoes have had an equal but opposite impact to that of $\mathrm{CH}_{4}$.

\section{Climate Change}

[16] The climate change $(\Delta T)$ attributable to Annex-IR emissions (Step 5) is computed using the MAGICC simple climate model [Wigley and Raper, 2001]. Different RF efficacies [Forster et al., 2007, Figure 2.19] are not included. Uncertainty is represented with a set of different parametric versions of the model: 9 equally likely values each for climate sensitivity; 9 for ocean diffusivity; and 7 for historical RF (Figure 2e). Each of these 567 models is assigned a likelihood based on the top-down constraint of how well it matches the observed temperature rise. This set of models is used to calculate the PDF for Annex-IR $\Delta \mathrm{T}$ using 7 equally likely scenarios for $\triangle \mathrm{RF}$ based on the PDF derived here (Figure S3). This simple climate model has no internal variability, although naturally forced decadal variability (e.g., volcanoes) is included via the RF history. The post-1990 Annex-IR $\Delta R F$ is calculated as a perturbation to a fixed, single-climate history, and thus the attributed $\Delta \mathrm{T}$ does not exhibit internal climate variability. In addition to $\Delta \mathrm{T}$ derived from the total $\Delta \mathrm{RF}$ (F-gases included as $2 \%$ of that of $\mathrm{CO}_{2}$ ), this process was repeated with individual components to produce PDFs of $\Delta \mathrm{T}$ 's for $\mathrm{CO}_{2}, \mathrm{CH}_{4}$, and $\mathrm{N}_{2} \mathrm{O}$ (Figure $2 \mathrm{f}$ ).

[17] The median value of Annex-IR $\Delta \mathrm{T}$ in January 2003 is calculated to be $+0.106^{\circ} \mathrm{C}$ with a slightly asymmetric $16 \%$ to- $84 \%$ confidence interval from $+0.077^{\circ} \mathrm{C}$ to $+0.140^{\circ} \mathrm{C}$. This final uncertainty range $(-27 \%,+32 \%)$ is almost twice that of the $\triangle \mathrm{RF}$ from which it is generated $( \pm 17 \%)$, confirming that climate modeling is the largest single uncertainty. Because of the constraint placed by the historical temperature record, uncertainty on this transient warming is less than that for an equivalent equilibrium warming [Frame et al., 2006]. The asymmetric PDF, with a longer tail at high $\Delta \mathrm{T}$, comes from climate models favoring large climate sensitivities.

\section{Discussion}

[18] In this paper, we derive and propagate the sources of uncertainty in attributing climate change to emissions activity from the developed countries by combining forward and inverse models (Figure 1). Specifically, we calculate the 19902002 temperature change $(\Delta \mathrm{T})$ attributable to Annex-IR that is consistent with the observed climate system, including atmospheric composition and climate feedbacks: $+0.11 \pm$ $0.03^{\circ} \mathrm{C}$. We expect this level of uncertainty is typical over decadal time scales and will increase over multi-decadal scales when long-term feedbacks increase uncertainty [Meehl et al., 2007, Figure 10.28]. Inclusion of internal variability or $\mathrm{RF}$ efficacy ranges in the model would somewhat increase this uncertainty. Gregory and Forster [2008] study the transient climate response (TCR), attributing total $\Delta \mathrm{T}$ to total $\triangle \mathrm{RF}$ using a range of models with internal variability, and calculate an uncertainty in this mapping of about $\pm 27 \%(68 \%$ confidence), similar to ours. Following their analysis of TCR for increasing $\triangle \mathrm{RF}$, our estimated Climate Resistance is $2.8 \mathrm{~W} \mathrm{~m}^{-2} \mathrm{~K}^{-1}$ at the upper end of their $90 \%$-confidence range for models and observations.

[19] The observed $\Delta \mathrm{T}$ includes other factors: the rest of the world's GHG emissions, aerosol forcing, non-Kyoto GHG like $\mathrm{O}_{3}$, volcanic cooling from Mt. Pinatubo, and internal climate variability. Using a linear fit over a longer period of observations, such as 1981-2003, we can average over some of this variability and derive an observed $\Delta \mathrm{T}$ of $+0.24 \pm$ $0.05^{\circ} \mathrm{C}$ for the period $1990-2002$. Much of this change is caused by non-Annex-IR emissions during this period, global GHG emissions prior to 1990, and cooling by aerosols. If global anthropogenic emissions of Kyoto GHGs were cut in 1990 , then reductions in $\mathrm{CO}_{2}, \mathrm{CH}_{4}$ and $\mathrm{N}_{2} \mathrm{O}$ by January 2003 would be about $28 \mathrm{ppm}, 650 \mathrm{ppb}$, and $17 \mathrm{ppb}$, respectively. This all-countries attributable temperature change is $+0.33^{\circ} \mathrm{C}$ (calculated with the PDF ensemble of probabilistic climate models but with only the central estimate for global $\Delta R F$ from Kyoto gases since an uncertainty analysis parallel to that 
of Annex-IR was not possible). Likewise, we calculate that anthropogenic aerosols have caused a cooling of $-0.73^{\circ} \mathrm{C}$ over this period, but this effect is short-lived. These results are consistent with observations if worldwide emissions of GHG prior to 1990 caused about $+0.6^{\circ} \mathrm{C}$ warming over 1990-2002 (see Table S4).

[20] Relative attributable warming is the essence of the Brazil proposal. For the ratio $\Delta \mathrm{T}_{\mathrm{A}-\mathrm{IR}} / \Delta \mathrm{T}_{\mathrm{All}}=0.11^{\circ} \mathrm{C} / 0$. $33^{\circ} \mathrm{C}$, the uncertainty in calculating $\Delta \mathrm{T}$ from $\Delta \mathrm{RF}$ would cancel if the two histories of $\Delta R F$ were proportional and contained the same ratio of GHGs. Since the mix of GHG emissions from non Annex-IR favors $\mathrm{CH}_{4}$ and $\mathrm{N}_{2} \mathrm{O}$ and is increasing more rapidly than that of Annex-IR, a more thorough, combined uncertainty analysis would propagate errors in GHG abundances from pre-1990 emissions as well as post-1990 emissions from non Annex-IR with constraints from the observed abundances. Given that our test case is for the restricted period 1990-2002 and that the $\Delta R F$ uncertainty encompasses the different mix of GHGs, we estimate uncertainty in the ratio $\Delta \mathrm{T}_{\mathrm{A}-\mathrm{IR}} / \Delta \mathrm{T}_{\mathrm{All}}=1 / 3$ to be $\pm 17 \%$ (i.e., the uncertainty in $\Delta \mathrm{T}$ modeling is correlated and cancels but that in $\triangle \mathrm{RF}$ remains). This relative uncertainty would increase if the period of emissions is extended backward to 1900 or the evaluation time is extended to 2100 since climate modeling uncertainties, e.g., early vs. late $\Delta R F$, would no longer cancel.

[21] Acknowledgments. UNFCCC requested evaluation of the Brazil proposal at first through a series of expert meetings and subsequently by requests from SBSTA for updates from the scientific community that were taken up by the ad hoc group MATCH (www.match-info.net) and reported to COP-13 at Bali. The governments of the U.K., Norway, and Germany supported participation of developing country scientists. JF received support from the Research Council of Norway and The Norwegian Ministry of Environment. JEP and MJP received support from NASA MAP program; and AKJ from NSF.

\section{References}

Andronova, N., and M. E. Schlesinger (2004), Importance of sulfate aerosol in evaluating the relative contributions of regional emissions to the historical global temperature change, Mitigation Adaptation Strategies Global Change, 9, 383-390.

Cao, L., and A. Jain (2005), An Earth system model of intermediate complexity: Simulation of the role of ocean mixing parameterizations and climate change in estimated uptake for natural and bomb radiocarbon and anthropogenic $\mathrm{CO}_{2}, J$. Geophys. Res., 110, C09002, doi:10.1029/ 2005JC002919.

den Elzen, M. G. J., and M. Schaeffer (2002), Responsibility for past and future global warming: Uncertainties in attributing anthropogenic climate change, Clim. Change, 54, 29-73.

den Elzen, M. G. J., et al. (2005), Analysing countries' contribution to climate change: Scientific and policy-related choices, Environ. Sci. Policy, 8, 614-636.

Denman, K. L., et al. (2007), Couplings between changes in the climate system and biogeochemistry, in Climate Change 2007: The Physical Science Basis, Working Group I Contribution to the Fourth Assessment Report of the IPCC, edited by S. Solomon, D. Qin, and M. Manning, chap. 7, pp. 499-587, Cambridge, Univ. Press, Cambridge, U. K.

Filho, M. L. G., and M. Miguez (1998), Technical note on the time dependent relationship between emissions of greenhouse gases and climate change, UNFCCC/AGBM/1997/MISC.1/Add.3 GE.97, Minist. of Sci. and Technol., Brasilia, Brazil.

Forster, P., et al. (2007), Changes in atmospheric constituents and in radiative forcing, in Climate Change 2007: The Physical Science Basis: working Group I Contribution to the Fourth Assessment Report of the IPCC, edited by Solomon et al., chap. 2, pp. 129-234, Cambridge Univ. Press, Cambridge, U. K.

Frame, D. J., D. A. Stone, P. A. Stott, and M. R. Allen (2006), Alternatives to stabilization scenarios, Geophys. Res. Lett., 33, L14707, doi:10.1029/ 2006 GL025801.
Gregory, J. M., and P. M. Forster (2008), Transient climate response estimated from radiative forcing and observed temperature change, J. Geophys. Res., 113, D23105, doi:10.1029/2008JD010405.

Hansen, J. E. (1988), The greenhouse effect: Impacts on current global temperature and regional heat waves, testimony to U.S. Senate Committee on Energy and Natural Resources, 100th Congress, 2nd Session, June 23, 1988.

Hegerl, G. C., et al. (2007), Understanding and attributing climate change, in Climate Change 2007: The Physical Science Basis: working Group I Contribution to the Fourth Assessment Report of the IPCC, edited by S. Solomon, D. Qin, and M. Manning, chap. 9, pp. 663-745, Cambridge Univ. Press, Cambridge, U. K.

Höhne, N., and K. Blok (2005), Calculating historical contributions to climate change: Discussing the Brazilian proposal, Clim. Change, 71, $141-173$.

Intergovernmental Panel on Climate Change (1997), Revised 1996 IPCC Guidelines for National Greenhouse Gas Inventories, edited by J. T. Houghton et al., Cambridge Univ. Press, Cambridge, U. K.

International Energy Agency (2004), $\mathrm{CO}_{2}$ Emissions From Fuel Combustion, Org. of Econ. Coop. and Dev., Paris.

Ito, A., et al. (2008), Can we reconcile differences in estimates of carbon fluxes from land-use change and forestry for the 1990s?, Atmos. Chem. Phys., 8, 3291-3310.

Jain, A. K., and X. Yang (2005), Modeling the effects of two different land cover change data sets on the carbon stocks of plants and soils in concert with $\mathrm{CO}_{2}$ and climate change, Global Biogeochem. Cycles, 19, GB2015, doi: $10.1029 / 2004 \mathrm{~GB} 002349$.

Marland, G., et al. (2003), Global $\mathrm{CO}_{2}$ emissions from fossil-fuel burning, cement manufacture, and gas flaring: 1751-2000, Carbon Dioxide Inf. Anal. Cent., Oak Ridge Natl. Lab., Oak Ridge, Tenn.

Meehl, G. A., et al. (2007), Global climate projections, in Climate Change 2007: The Physical Science Basis: working Group I Contribution to the Fourth Assessment Report of the IPCC, edited by S. Solomon, D. Qin, and M. Manning, chap. 10, pp. 747-845, Cambridge Univ. Press, Cambridge, U. K.

Mitchell, J. F. B., et al. (2001), Detection of climate change and attribution of causes, in Climate Change 2001: The Scientific Basis: Contribution fo Working Group I to the Third Assessment Report of the Intergovernmental Panel on Climate Change, edited by J. T. Houghton et al., pp. 569-572, Cambridge Univ. Press, Cambridge, U. K.

Olivier, J. G. J., and J. J. M. Berdowski (2001), Global emissions sources and sinks, in The Climate System, edited by J. Berdowski, R. Guicherit, and B. J. Heij, pp. 33-78, A. A. Balkema, Lisse, Netherlands.

Penner, J. E., et al. (2001), Aerosols, their direct and indirect effects, in Climate Change 2001: The Scientific Basis: Contribution of Working Group I to the Third Assessment Report of the Intergovernmental Panel on Climate Change, edited by J. T. Houghton et al., chap. 5, pp. 289-348, Cambridge Univ. Press, Cambridge, U. K.

Ramankutty, N., and J. A. Foley (1998), Characterizing patterns of global land use: An analysis of global croplands data, Global Biogeochem. Cycles, 12, 667-685

Ramankutty, N., and J. A. Foley (1999), Estimating historical changes in global land cover: Croplands from 1700 to 1992, Global Biogeochem. Cycles, 13, 997-1027.

Ramaswamy, V., et al. (2001), Radiative forcing of climate change, in Climate Change 2001: The Scientific Basis: Contribution of Working Group I to the Third Assessment Report of the Intergovernmental Panel on Climate Change, edited by J. T. Houghton, chap. 6, pp. 349-416, Cambridge Univ. Press, Cambridge, U. K

Rive, N., A. Torvanger, and J. Fuglestvedt (2006), Climate agreements based on responsibility for global warming: Periodic updating, policy choices, and regional costs, Global Environ. Change, 16, 182-194.

Rosa, L. P., S. K. Ribeiro, M. S. Muylaert, and C. P. de Campos (2004), Comments on the Brazilian proposal and contributions to global temperature increase with different climate responses: $\mathrm{CO}_{2}$ emissions due to fossil fuels, $\mathrm{CO}_{2}$ emissions due to land use change, Energy Policy, 32, $1499-1510$

Stott, P. A., et al. (2006), Observational constraints on past attributable warming and predictions of future, J. Clim., 19, 3055-3069.

Trudinger, C. M., and I. G. Enting (2005), Comparison of formalisms for attributing responsibility for climate change: Non-linearities in the Brazilian proposal, Clim. Change, 68, 67-99.

United Nations Framework Convention on Climate Change (UNFCCC) (2004), National greenhouse gas inventory data from Annex I Parties for 1990 to 2002, Rep. FCCC/WEB/2004/3, Bonn, Germany.

van Aardenne, J. A., F. J. Dentener, J. G. J. Olivier, C. G. M. K. Goldewijk, and J. Lelieveld (2001), A $1^{\circ} \times 1^{\circ}$ resolution data set of historical anthropogenic trace gas emissions for the period 1890-1990, Global Biogeochem. Cycles, 15, 909-928. 
Wigley, T. M. L., and S. C. B. Raper (2001), Interpretation of high projections for global-mean warming, Science, 293, 451-454.

N. Andronova and J. E. Penner, AOSS, University of Michigan, Ann Arbor, MI 48109-2143, USA.

J. S. Fuglestvedt and R. B. Skeie, CICERO, P.O. Box 1129 Blindern, N-0318 Oslo, Norway.

N. Höhne, Ecofys Germany, Eupener Strasse 59, D-50933 Köln, Germany.

A. K. Jain, Atmospheric Sciences, University of Illinois at UrbanaChampaign, Urbana, IL 61801, USA.

A. Kurosawa, Research and Development Division, Institute of Applied Energy, Tokyo 105-0003, Japan.
J. A. Lowe and P. A. Stott, Met Office, Reading RG6 6BB, UK.

L. Pinguelli, COPPE, University of Rio de Janeiro, Rio de Janeiro $21945-$ 970, Brazil.

C. Pires de Campos, PETROBRAS, Avenida Horacio de Macedo, 950, sala 9009A, Rio de Janeiro 21941-915, Brazil.

M. J. Prather, Earth System Science, University of California, Irvine, CA 92697-3100, USA. (mprather@uci.edu)

S. C. B. Raper, CATE, Manchester Metropolitan University, Manchester M1 5GD, UK

J. van Aardenne, JRC, Institute for Environment and Sustainability, I-21020 Ispra, Italy.

F. Wagner, IIASA, Laxenburg A-2361, Austria. 